\title{
Nerve Growth Factor, Neural Stem Cells and Alzheimer's Disease
}

\author{
Klaus Heese ${ }^{\mathrm{a}}$ Jin Wei Low ${ }^{\mathrm{a}}$ Noriko Inoue ${ }^{\mathrm{b}}$ \\ ${ }^{a}$ Department of Molecular and Cell Biology, School of Biological Sciences, Nanyang Technological University, \\ Singapore, and ${ }^{\mathrm{b}}$ Medical Center for Translational Research, Osaka University Hospital, Suita, Osaka, Japan
}

\section{Key Words}

Alzheimer's disease - Apoptosis - Nerve growth factor •

Neurodegeneration $\cdot$ Neurotrophin $\cdot$ Neural stem cells

\begin{abstract}
The protein family of the neurotrophins (NTs) comprises structurally and functionally related molecules such as nerve growth factor (NGF) which influences the proliferation, differentiation, survival and death of neuronal cells. In addition to their established functions for cell survival, NTs also mediate higher brain activities such as learning and memory. Changes in NT expression levels have thus been implicated in neurological diseases such as Alzheimer's disease (AD), an age-related neurodegenerative disorder that is characterized by progressive loss of memory and deterioration of higher cognitive functions. The present review provides an overview of the functional role of NGF in neural stem cells and $A D$ while pointing to a potential application of this peptide for the treatment of AD.
\end{abstract}

Copyright $\odot 2006$ S. Karger AG, Basel

\section{Introduction}

Nerve growth factor (NGF), brain-derived neurotrophic factor (BDNF), neurotrophin-3 (NT-3), and neurotrophin-4/5 (NT-4/5) are members of the neurotrophin (NT) gene family that supports the survival of specific neuronal populations, including those that are affected by neurodegeneration in Alzheimer's disease (AD). NGF maintains the survival of cholinergic neurons of the basal forebrain system, nociceptive dorsal root ganglion neurons and some third-order sympathetic neurons, while BDNF supports cholinergic, dopaminergic neurons as well as those containing 5-hydroxytryptamine and neuropeptides. NT-3 was shown to prevent the death of adult central noradrenergic neurons in vivo [1-4]. In $\mathrm{AD}$ the primary regions affected are the hippocampus, cerebral cortex and amygdala. Neuronal loss involves in particular the cholinergic neurons of the basal forebrain system and those of the noradrenergic and serotonergic system. NGF promotes survival of those neurons by activating its specific high-affinity tyrosine kinase receptor TRKA, while downstream of TRKA, the small G-protein p21 ras plays a pivotal role in controlling neuronal survival and differentiation. We have shown that in AD brain TRKA expression is downregulated [5-7]. Various reports also demonstrated increased levels of NGF in cortical and subcortical brain areas including the frontal and parietal cortices and the hippocampus. These increases were attributed to both reduced uptake and retrograde transport of NGF to NGFsensitive cell bodies, since the expression and protein levels of TRKA were reduced in target regions of basal fore-

Supported by a grant (SBS/SUG/22/04) to K.H. from Nanyang Technological University.

\section{KARGER \\ Fax +41613061234 E-Mail karger@karger.ch} www.karger.com

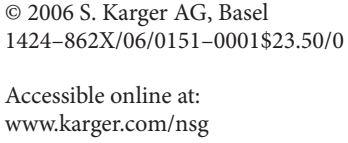

Dr. Klaus Heese

Department of Molecular and Cell Biology, School of Biological Sciences

Nanyang Technological University, 60 Nanyang Drive

637551 Singapore (Singapore)

Tel. +65 6316 2848, Fax +65 6791 3856, E-Mail kheese@ntu.edu.sg 
brain cholinergic neurons, such as the cortical association areas. Of particular interest is the increased expression of proNGF in $\mathrm{AD}$ subjects as it is considered to mediate a pro-apoptotic signal through the activation of the NT receptor $\mathrm{p} 75^{\mathrm{NTR}}$ [8-10]. In contrast, BDNF messenger RNA levels were reported to be lowered in hippocampal neurons and protein levels decreased in the entorhinal and parietal cortex of patients with $\mathrm{AD}$. These results point to an antagonistic involvement of NGF and BDNF, both of which are associated with trophic support of cholinergic neurons of the basal forebrain system, in the neuropathology of AD.

$\mathrm{AD}$ is the most common cause of dementia among people of age 65 and older. It is a progressive neurodegenerative disorder characterized by impaired memory and cognition. The treatment of $\mathrm{AD}$ remains a major challenge because of the incomplete understanding of triggering events that lead to the selective neurodegeneration characteristic of $\mathrm{AD}$ brains. In the past decade it has become evident that the clinical and histopathological phenotypes of $\mathrm{AD}$ are caused by heterogenous genetic and possibly environmental factors. Several genes, including amyloid precursor protein (APP), presenilin-1 (PS-1) and PS-2, have been identified as the possible cause of most familial forms of the disease. Although several genetic defects have been identified in patients with a family history of this disease, the majority of $\mathrm{AD}$ cases has a late-onset (over the age of 65) and involves individuals with no known genetic predisposition. One major genetic risk factor for the disorder in the typical late-onset period was provided by the discovery of the predisposition of the $\varepsilon 4$ allele of apolipoprotein $\mathrm{E}$ (ApoE) to $\mathrm{AD}$. Inheritance of one or two $\varepsilon 4$ alleles increases the likelihood of developing $\mathrm{AD}$ and makes its mean age of onset earlier than in subjects harboring $\varepsilon 2$ or $\varepsilon 3$ alleles [11-14]. The disease is characterized by the presence of neuritic amyloid plaques, cerebrovascular amyloidosis and neurofibrillary tangles (NFTs). The AD brain exhibits extracellular plaques of aggregated amyloid- $\beta$-peptide $(A \beta)$ and intracellular NFTs containing hyperphosphorylated TAU protein. Usually, the hippocampal area, perforant path, and entorhinal cortex exhibit NFTs earliest in the course of AD. Among cortical association areas, the parietal cortex shows deposition of $A \beta$ plaques, NFTs, and neuronal loss earlier than the frontal cortex, whereas the cerebellum is usually preserved. A $\beta$ is generated from its APP via sequential proteolytic cleavages by $\beta$ - and $\gamma$-secretases. It is widely believed that the $A \beta$ plaques are the primary cause of neurotoxicity and subsequent neuronal cell death in the brains of $\mathrm{AD}$ patients [11-14].
For decades, scientists investigating APP have focused on its pathogenic role in the brains of AD patients because the prevalence of the $A \beta$ toxicity theory in $A D$ pathology tends to limit the focus of research on its pathophysiological function. As such, the physiological role of APP is still not well understood. However, based on its sequence conservation throughout evolution, it is likely that APP has important functions to fulfill. Understanding these functions of APP would contribute towards a better understanding of the molecular pathogenesis of $\mathrm{AD}$, and ultimately facilitate the design of therapeutic strategies. Studies show that APP is conserved among mammalian species, and homologues have been identified in human (APLP1, APLP2), mouse, Drosophila melanogaster and Caenorhabditis elegans [15-17]. Its conservation throughout evolution suggests that APP plays an important role in brain function in vivo. For instance, APP is a mediator of neurite outgrowth, and may be involved in neural development and synaptic plasticity [18]. The function of APP is probably dispensable for mouse embryogenesis and development, since APP knockout mice were able to survive to birth. Alternatively, its function could be compensated for by APP homologues. However, APP's implication in intra-neuronal calcium regulation and G-protein signaling events may explain the observation obtained from APP knockout studies showing age-related cognitive deficits due to impaired long-term potentiation. This indicates that APP, and most probably A $\beta$ are indispensable components for higher brain function [19-23].

APP is expressed abundantly by almost all cells and is present in high amounts in neurons of the central nervous system (CNS). Alternative splicing generates several isoforms of APP of which $\mathrm{APP}_{695}$ is expressed predominantly in neurons $[24,25]$. The expression of APP resembles that of a typical housekeeping gene, and can be found in a variety of organs [26]. In the CNS, APP is widely distributed and exists in the cytoplasm, dendrites and axons of the neurons [27]. Several roles have been proposed for APP in this region.

APP undergoes at least three different processing pathways. In the constitutive secretory pathway, APP is cleaved by a membrane-associated $\alpha$-secretase within the $A \beta$ domain, releasing the soluble extracellular domain of APP $(\mathrm{sAPP} \alpha)$. This pathway is non-amyloidogenic because the cleavage precludes the formation of $A \beta$ [28]. In the alternative pathway, APP is first cleaved in the extracellular domain by the $\beta$-site APP-cleaving enzyme BACE1, followed by a $\gamma$-secretase cleavage within the transmembrane domain of the stub generated by $\beta$-cleavage, liberating the 39-43 amino acid $A \beta$ peptide. Concurrent $\varepsilon$-site 
cleavage generates the APP intracellular domain (AICD) fragment which translocates to the nucleus and acts as a signaling molecule involved in transcriptional activation [29-32]. However, neither the intermediate $A \beta$ peptide, which ends at the $\varepsilon$-cleavage site, nor the $\mathrm{C}$-terminal fragment starting with an $\mathrm{N}$-terminus generated by $\gamma$-cleavage, has ever been detected. One possibility is that $\gamma$ - and $\varepsilon$-cleavages occur simultaneously. The other possibility is that there may be additional cleavages between the $\gamma$ - and $\varepsilon$-cleavages. Indeed, the new cleavage site identified at $\mathrm{A} \beta_{46}$ was designated as the $\zeta$-cleavage site. It is also noted that the new $\zeta$-cleavage site at $A \beta_{46}$ is the APP717 mutation site. The new cleavage is within the transmembrane domain and a Presenilin-dependent event [33].

While the protein complex, consisting of Presenilin, Nicastrin, Pen 2 and Aph1, controls the $\gamma$-cleavage site of APP, the Reticulons indirectly control the $\beta$-cleavage site of APP via interaction with BACE. An increase in the Reticulon protein reduces the production of $A \beta$. The other protein Alcadein (Alc) forms a protein complex with APP and X11L (X11L, also known as the APP-binding-familyA-member-2 (APBA2)), thereby regulating APP metabolism and suppressing $A \beta$ production. The metabolism of Alc resembles that of APP including the Presenilin-dependent $\gamma$-cleavage mechanism. In addition to the effect of mutations in Presenilin or APP, any imbalance in the metabolism of Reticulon, Alc and APP may influence the Fe65-dependent gene transactivation, which together with increased secretion of $A \beta$ may contribute to neurodegeneration in $\mathrm{AD}$ [14].

The $A \beta$ peptide is a normal product of cells $[34,35]$. Around $90 \%$ are $A \beta_{40}$, a fairly soluble form of the peptide; the remaining are $A \beta_{42}$ and $A \beta_{43}$ peptides which are highly fibrillogenic, and are deposited selectively in amyloid plaques [36-38]. Under normal conditions, the concentration of $A \beta$ is tightly controlled by degradation enzymes and maintained below the threshold for aggregation into $\beta$-sheet fibrils [39]. Recent discoveries show that $A \beta$, while toxic and $\mathrm{AD}$ causing if overproduced, has a physiological and non-toxic function. It regulates cellular lipid levels. In specialized regulatory cycles $A \beta$ controls the cholesterol synthesis by lowering hydroxymethylglutarylCoA reductase activity and sphingomyelin levels. These lipids control the activity of the enzyme producing $A \beta$, resulting in altered $A \beta$ levels. Interference with these regulatory cycles by pharmacological, genetic, or even dietary means, changes $A \beta$ production and thus the risk for $A D$. Knowledge of the physiological function of $A \beta$ allows us to reevaluate the therapeutic and preventive approaches and to generate more specific and novel therapies for the treatment of $\mathrm{AD}$. It also explains the functional link between $\mathrm{AD}$ and cholesterol and how statins (cholesterollowering drugs) work to prevent $\mathrm{AD}$ [35].

The net accumulation of $A \beta$ peptides (especially the amyloidogenic $A \beta_{42}$ isoform) plays a central role in the pathogenesis of $\mathrm{AD}$, and likely reflects the cumulative effect of multiple events, including the abnormal regulation and misprocessing of APP. The accumulation of A $\beta$ initiates a series of downstream neurotoxic events, such as impairment of membrane transporters, destabilization of cellular calcium homeostasis, and the hyper-phosphorylation of TAU, resulting in neuronal dysfunction and death $[11,12,14,36]$.

Despite advances in our understanding of the basic biological roles of APP, the normal physiological functions of APP in learning and memory still remain unclear. It has been proposed that changes in the activity of the different $\mathrm{A} \beta$ fragments as a result of altered APP processing during the course of $\mathrm{AD}$ may also contribute to cognitive dysfunction. With these new developments researchers are now focusing more on elucidating the physiological actions of soluble $A \beta$, and the normal functions performed by APP in the brain. A $\beta$ exhibits the capacity to exert powerful regulatory control over key neural functions including cell excitability, synaptic transmission and longterm potentiation, both acutely and over the long-term for neural plasticity $[14,40,41]$. For instance, a recent report has proposed a negative feedback model in which the activity-dependent modulation of $\mathrm{A} \beta$ production participates in keeping neuronal hyperactivity under control. In this model neural activity regulates $\beta$-secretase actions on APP. Thus, neuronal activity regulates the production and secretion of $A \beta$ by controlling APP processing upstream of $\gamma$-secretase activity. Moreover, while the formation of $\mathrm{A} \beta$ depresses synaptic transmission, synaptic depression decreases neural activity. Any disturbance in this feedback loop may contribute to an increase in $A \beta$ formation and neuronal toxicity in $\mathrm{AD}$ [41].

\section{$A D$ and the NGF System}

Neurotrophic factors have attracted much attention regarding their potential as a remedy for neurological disorders. In this regard, NGF has generated great interest as a potential target for the treatment of AD. This interest is based on the observation that cholinergic neurons of the basal forebrain (CBFs), which provide the major source of cholinergic innervation to the cerebral cortex and hippocampus, undergo selective and severe degeneration in ad- 
vanced $A D$ and that the survival of $C B F$ neurons depends upon NGF and its receptors, TRKA and $\mathrm{p} 75^{\mathrm{NTR}}$. Dysfunction of NGF and its high (TRKA) and low (p75 ${ }^{\mathrm{NTR}}$ ) affinity receptors has been suggested to underlie the selective degeneration of the nucleus basalis (NB) cholinergic cortical projection neurons in the end stage of AD. Whether the NGF system is dysfunctional during the prodromal stages of AD has only recently been evaluated [5-10, $42-$ 45]. Surprisingly, the number of neurons containing choline acetyltransferase (ChAT, enzyme-synthesizing neurotransmitter acetylcholine) remains stable despite a significant reduction in NGF receptor-positive cells in people with mild cognitive impairment. This suggests a phenotypic NGF receptor downregulation but not an obvious loss of $\mathrm{NB}$ neurons during prodromal AD. Furthermore, there is an increase in proNGF levels (precursor of mature NGF) and a loss of cortical TRKA in the face of stable p75 ${ }^{\text {NTR }}$ (which has a high affinity for proNGF and may convey a pro-apoptotic signal [8]) during the early stage of $\mathrm{AD}$. Depending on the cellular context these changes may result in increased pro-apoptotic signaling, cell survival, or a defect in retrograde transport mechanisms [14]. Alterations in NGF and its receptors within the cholinotrophic NB system in early AD suggest that NGF-mediated cell signaling is required for the long-term survival of these neurons. Therapeutic neurotrophic intervention might delay or prevent NB neuron degeneration and preserve cholinergic cortical function during prodromal $\mathrm{AD}$ [42-45]. With regard to these findings, it is interesting to mention that an anti-NGF-antibody animal model shows typical features of $\mathrm{AD}$ [46-48]. The aged anti-NGF transgenic mice acquire an age-dependent neurodegenerative pathology including amyloid plaques, insoluble and hyperphosphorylated TAU, and NFTs in cortical and hippocampal neurons. Extensive neuronal loss throughout the cortex and cholinergic deficits in the basal forebrain were also observed as well as behavioral deficits. The recognition memory deficits in these transgenic mice were then shown to be rescued by administering intranasal NGF [49]. These results demonstrate that a deficit in the signaling and transport of NGF leads to neurodegeneration. The overall picture is strikingly reminiscent of human $\mathrm{AD}$.

\section{APP and NGF Signaling}

One of the more interesting aspects of APP is its function as a kinesin-I membrane receptor mediating the axonal transport of cargo proteins such as BACE, PS-1,
GAP43, synapsin, the 'Sunday-driver' SYD and TRKA [50-54]. The carboxy-terminus mediates binding of APP to the motor protein (kinesin light chain of kinesin-I), whereas the $A \beta$ region might be an essential part of the sorting signal for axonally transported vesicles [50-52, 55]. This raises the possibility that axonal damage might induce APP proteolysis to release the AICD, which might then transmit an injury signal to the cell body where it relocalizes to the nucleus mediating gene transcription via (direct or indirect) interaction with $\mathrm{Fe} 65,14-3-3 \gamma$, Tip60 (a histone acetyltransferase) and CP2 ( $\alpha$-globin transcription factor, also known as LSF or LBP-1) [30, 56-59].

APP seems to be directly involved in regulating apoptotic signaling pathways through its interaction with the 'Sunday-driver' SYD (also known as JSAP1 or JIP3) and JIP1b/2 because SYD acts as a scaffolding protein for the JNK/MAPK (c-Jun N-terminal kinase, mitogen-activated kinase) cascade and the SYD-JNK3 pathway has been shown to be required for signaling upon nerve injury and stress-induced neuronal apoptosis [54, 60-70]. Corroborating data confirmed that mutations in APP connect pro-apoptotic APP-signaling with the JNK pathway [69, 71].

Another exciting discovery is the modulation of APP phosphorylation by the NGF receptor TRKA (fig. 1) to couple APP via the Shc/Grb2 adaptor proteins to cellular pathways generally associated with proliferation and survival, including the Ras/MAPK pathway and the PI3K/ PKB (phosphatidylinositol 3-kinase, protein kinasese-B) signal transduction cascade [72-75]. Thus, considering the fact that the NGF-TRKA system is functionally disturbed in AD [5-10, 42-45], an impaired NGF-TRKAsignaling cascade may affect APP transport and signaling, thereby mediating apoptosis via: (i) a retrograde transport of AICD; (ii) the SYD-activated JNK/p38MAPK pathway, or (iii) an inhibited ras/MAPK-PI3K signaling. A deregulation of intracellular transport mechanisms caused by a deteriorated APP/TRKA-NGF-signaling cascade might be one crucial aspect for the initiation of neurodegeneration in $\mathrm{AD}$. Recent results on the anterograde and retrograde transport of NTs will probably help to intensify studies about APP-mediated signaling mechanisms [7678].

In addition to the APP-TRKA interaction, the NGF and the APP systems show a special interplay between $A \beta$ and $\mathrm{p} 75^{\mathrm{NTR}}$. While NT-activated $\mathrm{p} 75^{\mathrm{NTR}}$ is able to mediate an anti- or pro-apoptotic signal, the A $\beta-p 75^{\mathrm{NTR}}$ signal transduction pathway and its impact on $\mathrm{AD}$ are still unsolved problems $[8,79-85]$. At this point, it is of utmost 


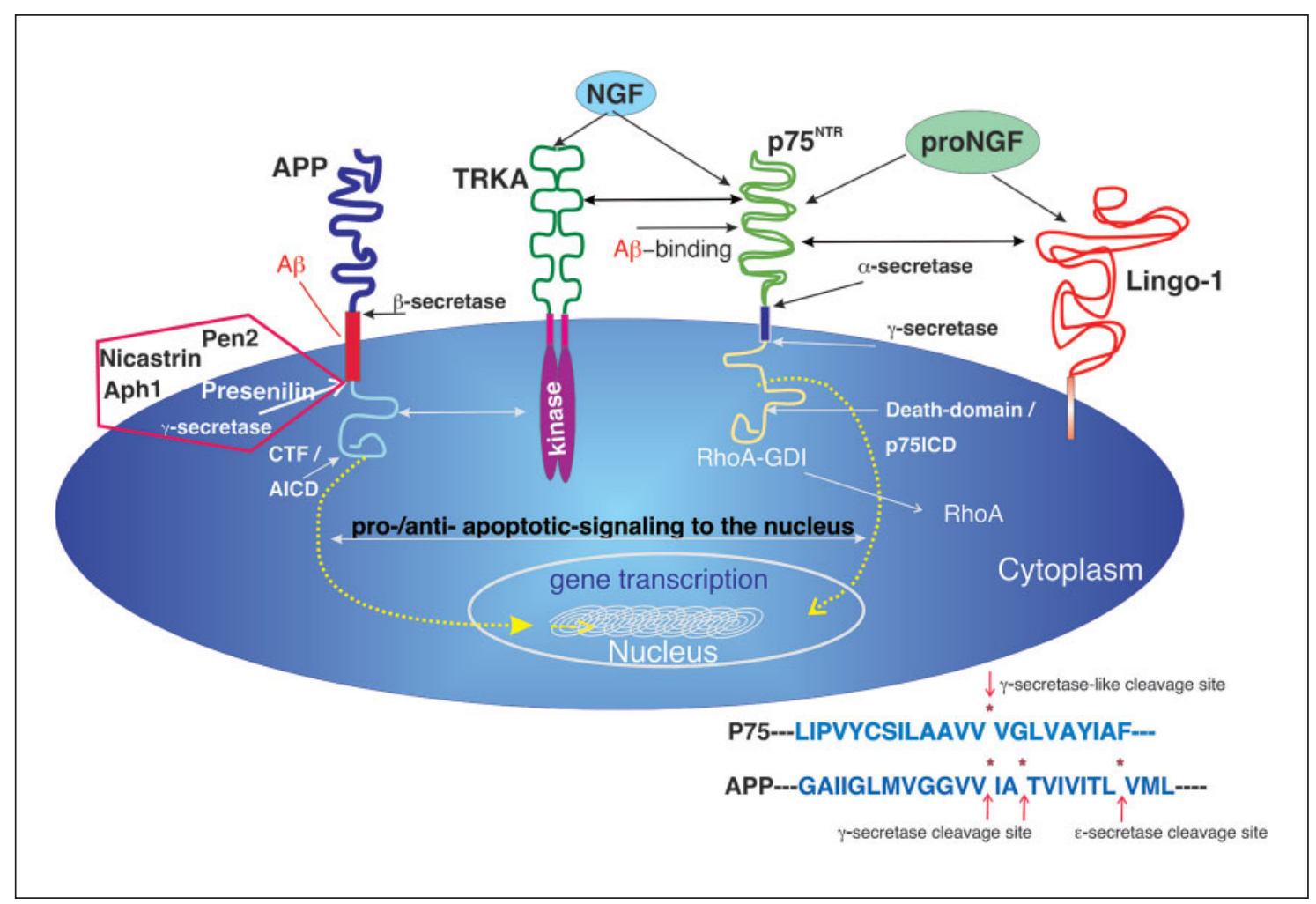

Fig. 1. Potential interactions among the NGF receptors TRKA and $\mathrm{p} 75^{\mathrm{NTR}}$, and APP involved in AD. To some extent, a comparison of the $\gamma$-cleavage sites of APP and p $75^{\text {NTR }}$ shows homologous sequences. While TRKA can modulate APP signaling directly via its phosphorylation, $A \beta$ is able to bind and activate the receptor $\mathrm{p} 75^{\mathrm{NTR}}$. NGF binds TRKA with high affinity and p $75^{\text {NTR }}$ with low affinity. In contrast, proNGF can bind p $75^{\text {NTR }}$ with high affinity.

interest that $\mathrm{p} 75^{\mathrm{NTR}}$ is processed by a $\gamma$-secretase enzyme in a similar way to APP, releasing p75ICD to transmit a signal to the nucleus (fig. 1). Another interesting aspect is the involvement of $\mathrm{p} 75^{\mathrm{NTR}}$ in triggering small GTP-binding protein-signaling pathways and the activation of Gproteins by APP as revealed by recent findings [8]. Although the downstream effects of $G_{0}$ by APP are completely unknown, the significance of G-proteins in directing neural activity and synaptic plasticity is well established and there are various possible ways in which APP-mediated G-protein regulation could influence higher cognitive functions $[22,23,86]$. Thus, for our understanding of neurodegenerative processes in $\mathrm{AD}$ we need an enlightenment of the physiological role of APP and its processed products AICD and A $\beta$. Moreover, the cross-talk among APP's and NGF-receptor's signaling cascades will be an interesting topic for further explorations.

\section{AD and Neural Stem Cells}

In recent years it has been noted that the adult brain has the 'self-repair capacity' to replace lost neurons in several selected regions of the CNS, such as the olfactory bulb, hippocampus, adult human subependymal zone and the cortex. Active neurogenesis occurs in the subgranular zone (SGZ) of the hippocampal dentate gyrus, and in the subventricular zone (SVZ) of the lateral ventricles. Neural stem cells (NSCs) within these neurogenic regions can proliferate and differentiate into neurons or glia, providing a reservoir for replacement of cells lost during normal cell turnover and after brain injury. Neurogenesis involves the self-renewal and proliferation of NSCs, as well as its differentiation into neurons and glia. Newborn neurons and glia then migrate to appropriate regions in the brain, and integrate into neuronal circuits [87-93]. Neurogenesis comprises different stages, including cell proliferation, mi- 
gration and differentiation which are tightly regulated by both intrinsic and extrinsic factors [94]. It plays important roles in adaptive responses to environmental demands, and is implicated in the learning and memory processes as well as recovery from injury which suggests that abnormalities in neural precursor cells may contribute to the pathogenesis of cognitive disorders such as AD [95]. Recent findings show that impairment of neurogenesis is sufficient to deteriorate learning and memory in rodents, hinting at a role played by abnormalities in the proliferation and differentiation of NSCs in the pathogenesis of disorders in learning and memory such as those in $\mathrm{AD}$ [96].

In the early stages of $\mathrm{AD}$ there is a relatively discrete population of neurons affected. Thus, the disease offers a relatively discrete target for potential therapies making it an ideal target for cell replacement therapy using endogenously activated NSCs. Estimations of the number and proliferative capacity of these cells suggest that mobilizing endogenous stem cells already present in the brain or transplantation of exogenous cells to replace lost cells, may be a realistic therapeutic approach. The question facing modern medicine is how best to use NSCs to produce functional recovery in neurodegenerative disorders in the aging brain [88, 90, 91, 93].

Preliminary evidence indicates that NSCs may play a role in the pathogenesis of AD. For instance, $A \beta$ inhibits proliferation, promotes apoptosis of human cortical stem cells in culture and impairs neurogenesis which is found to be altered in the brains of $\mathrm{AD}$ patients. Accumulation of aggregated $A \beta$ can impair cortical neurogenesis in the $\mathrm{AD}$ brain, where neuronal differentiation of NSCs is all the more essential for the replacement of degenerating neurons. Therefore, in addition to synaptic dysfunction and death of mature neurons, this reduced production of new neurons from NSCs within neurogenic niches of the $\mathrm{AD}$ brain may contribute to the pathogenesis of the disease. Thus, proliferation and migration in the SVZ is disrupted by the $A \beta$ peptide, as indicated by in vivo studies in mice $[97,98]$. Targeting NSCs as a therapeutic approach for the treatment of $\mathrm{AD}$ remains a challenging exercise. With regard to $\mathrm{AD}$, a thorough investigation has already shown that a mixture of epidermal growth factor (EGF), basic fibroblast growth factor (bFGF), retinoic acid and NGF can influence proliferation, migration, and phenotype lineage of stem cells in the brain of adult animals with a selective lesion of cholinergic neurons in the basal forebrain. Other than an increase in proliferation in the SVZ, authors could also demonstrate elevated ChAT activity in the hippocampus accompanied by an improved water maze test performance of those mice [99].
The data obtained by Haughey et al. [97, 98] show that $A \beta$ inhibits proliferation and migration of NSCs. However, recent data also suggest that $A \beta$ does not impair the neurogenic rate in NSC progeny, but instead increases the total number of neurons in vitro. Neurogenesis is induced by $A \beta_{42}$ but not by $A \beta_{40}$ and the neurogenic effect of $A \beta$ is not dependent on soluble factors released from the NSC progeny. These results suggest that $A \beta$ may have positive as well as deleterious actions, and that knowledge of the mechanisms involved in the former could be valuable in preventing and treating $\mathrm{AD}$ [100-102]. If a general feature of AD is the loss of proliferation of NSCs, then loss of proliferation in the SGZ of the hippocampus may contribute to the observed loss of memory in AD. This is suggested by the decreased proliferation of neural precursors in models of $\mathrm{AD}$ caused by the $\mathrm{A} \beta$ peptide, which may be exacerbated by the general loss of proliferation in the SGZ associated with aging. However, the exact role of NSCs in $\mathrm{AD}$ has yet to be elucidated $[91,100,103,104]$.

Several findings have also hinted at the involvement of APP itself in the regulation of neurogenesis. It has been reported that APP may act as an autocrine factor to stimulate cell proliferation, and is also able to mediate the effects of NGF on neurite outgrowth [18]. Recent studies have implicated sAPP $\alpha$, the secreted N-terminal non-amyloidogenic form, as a cofactor of EGF in the stimulation of responsive NSCs in the SVZ of the adult brain [105, 106]. In addition, it has been reported that excess APP in the environment causes glial differentiation of stem cells [103]. These findings create the possibility that APP itself may be involved in the regulation of neurogenesis that contributes to normal brain functions. This suggests that changes in the levels of APP could have a similar influence on the activity of neurogenic regions of the adult brain and that SAPP $\alpha$ plays an important active role in neurogenesis.

\section{NSCs and the Neurotrophins}

Stem cells obtained from an adult brain can generate all cell types when adequately stimulated in vitro. However, NSCs have an extremely limited ability, if any, to activate themselves in the case of brain damage. Human mesenchymal stem cell subpopulations express a variety of neuro-regulatory molecules, including the NTs, and promote neuronal cell survival and neuritogenesis. The expression of NTs in NSCs has been shown by different groups of researchers. Therefore, NSCs transplanted at sites of nerve injury are thought to promote functional 


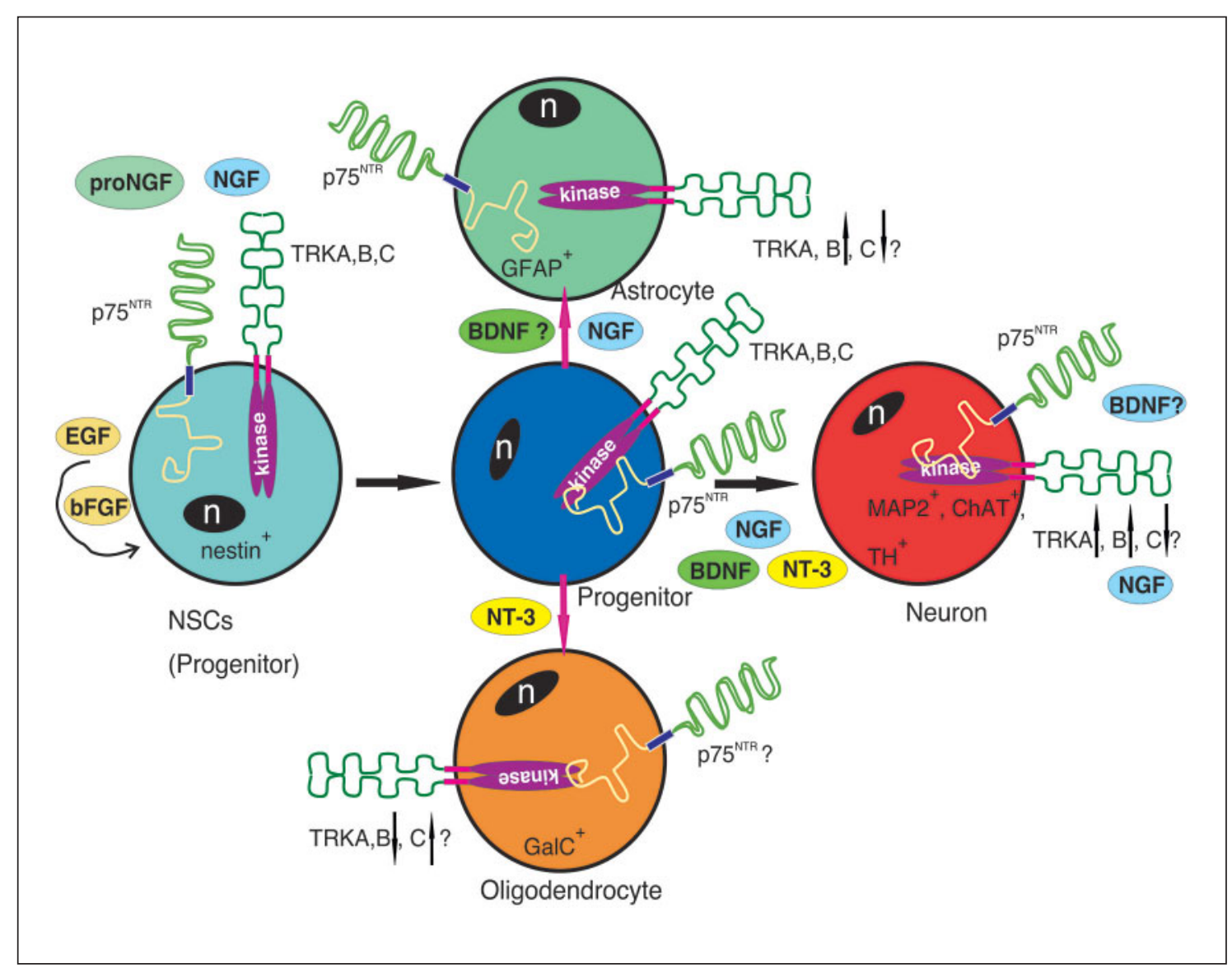

Fig. 2. Expression of the neurotrophin receptors TRK $(\mathrm{A}, \mathrm{B}, \mathrm{C})$ and $\mathrm{p} 75^{\mathrm{NTR}}$ during neural stem cell differentiation. ChAT $=$ Choline acetyltransferase; GalC = galactocerebroside; GFAP = glial fibrillary acidic protein; MAP2 = microtubule-associated protein-2; $\mathrm{n}=$ nucleus; $\mathrm{TH}=$ tyrosine hydroxylase. While NGF and BDNF promote the differentiation into neurons and astrocytes via the activation of the $\mathrm{p} 75^{\mathrm{NTR}}$ and the TRKA/B receptors, NT-3 promotes rather the differentiation into the neuronal/oligodendrocyte lineage.

recovery by producing trophic factors that induce survival and regeneration of host neurons [99, 107-109].

However, as of present, the increase in cell proliferation and differentiation into mature phenotypes has been described in very few experimental models of neurodegenerative diseases. For instance, in ischemic lesions, a transient and regional specific increase has been demonstrated in cell proliferation in the SVZ, cerebral cortex and hippocampus, where newly generated cells differentiate into a neuronal phenotype. But the efficiency of this cell replacement is limited, because the majority of newly generated neurons die shortly after generation [110]. Even endogenous NSCs seem to be unable to react in different experimental conditions involving lesions to selective neural populations; transplantation of NSCs at sites of neuronal degeneration is a very promising approach for the treatment of different neurological diseases such as $\mathrm{AD}[91,100,103,104]$.

Previously it has been shown that BDNF can promote survival, but not differentiation, of neurons arising from the forebrain subependymal zone [111]. Conversely, BDNF has been reported to enhance both survival and differentiation of neurons derived from EGF-responsive postnatal hippocampal stem cells [112]. NGF, in conjunction with bFGF, stimulates proliferation of striatal precursor cells [113].

Purified SVZ cells express not only the NTs but also their receptors $\mathrm{p} 75^{\mathrm{NTR}}$, TRKB and TRKC, but probably no TRKA [109]. Application of exogenous NTs, including NGF, BDNF, and NT-3, to these cells stimulates dendrit- 
ic growth and leads to complex dendritic arbors during the initial 3 days in culture. These studies seem to suggest that the effects are mediated by the $\mathrm{p} 75^{\mathrm{NTR}}$-activated signaling pathways rather than via the TRK receptors. BDNF is the only NT that is able to influence late-phase dendritic development via activation of its specific upregulated TRKB receptor. Thus dendritic arbor development of SVZ-derived neuronal cells may be regulated by NTs through the activation of $\mathrm{p} 75^{\mathrm{NTR}}$ and the TRKB receptor signaling pathways in a sequentially defined temporal pattern [109]. Of particular interest is the observation that $\mathrm{p} 75^{\mathrm{NTR}}$ seems to be essential for the differentiation of neural precursor cells activated with BDNF in the absence of EGF [114].

Early neurosphere cell studies (non-clonal) indicated that EGF had to be removed from the cultures in order to see a NT-mediated effect on differentiation [115]. In these studies, both BDNF and NGF induced neuronal differentiation, while removal of EGF led to astroglial differentiation. The more recent study by Benoit et al. [116] from the same laboratory is in agreement with our observation (unpublished) and shows expression of $\mathrm{p} 75^{\mathrm{NTR}}$ and all TRK (A, B and C) receptors for NGF, BDNF, and NT-3 on neurosphere cells, confirming and extending previous data [115]. In population studies on neurosphere cells they had previously demonstrated the potent differentiation effects of both BDNF and NGF when EGF, the primary stimulus, was removed before the addition of these two NTs $[115,116]$. Removal of EGF from neurosphere cells resulted in cessation of cell proliferation and pronounced astrocytic (glial fibrillary acidic protein positive) differentiation. Neuronal (neurofilament positive) and oligodendroglial (galactocerebroside positive) cells appeared in cultures treated with NTs. Treatment with NGF resulted in bipolar neuronal cells and stimulation by BDNF led to multipolar neuronal cells while treatment with NT-3 resulted in bipolar neuronal cells and oligodendrocytes (galactocerebroside positive). Upon NGFmediated neuronal differentiation neuronal cells expressed ChAT+ and, to a lesser degree, tyrosine hydroxylase. During differentiation into astrocytes and neurons, the TRKB receptor is rather upregulated and the TRKC receptor is downregulated while the TRKA receptor remains at a relatively high expression level. In contrast, differentiation into oligodendrocytes seems to follow a NT-3/TRKC-dependent mechanism. Although several groups have shown that various NTs support survival of oligodendrocytes, NT-3 seems to be the major NT (in addition to other neurotrophic factors such as ciliary neurotrophic factor) responsible for directing NSCs into oli- godendroglial cells. These studies demonstrate that NTs influence the fates of these multipotential precursor cells [111-121].

Considering clonal single NSC growth, it has been shown that withdrawal of EGF leads to time-dependent effects of both BDNF and NGF changing both gross colony morphology and lineage expression. BDNF and NGF show no effects on cell proliferation (if NSCs are cultured with EGF and BDNF or NGF) when compared to EGF controls and removal of EGF is permissive for the differentiating effects of BDNF and NGF. These data also indicate that isolated neurosphere cells that grow in EGF have about 50\% tri-lineage cells when stimulated with either BDNF or NGF for 14 days. While BDNF acts immediately, NGF effects can be seen at later points only. This could indicate that NGF works on a cell type that is less differentiated, or alternatively that these NTs have differential effects on inducing more NT receptors in different cell classes. These data further indicate that the majority of EGF neurosphere clones have NT-dependent tri-lineage potential. Removal of EGF with subsequent addition of BDNF or NGF results in an increase in neuronal and astroglial cells, but not oligodendrocytes [116]. At this point it is important to note that differences in NT receptor expression levels and NT responsiveness by numerous groups could be due to differences in cell concentration or the addition of serum, a potent astroglial inducing entity $[115,116,122,123]$. The actions of BDNF and NGF on EGF-responsive clonal neurosphere differentiation are most probably due to induced differentiation, and not cell survival or proliferation. The enhanced total proliferation within the colonies is not the mechanism for increased neuronal or astroglial lineages. However, without the capacity to individually map all cells in a colony, the possibility of selected outgrowth of one cell population with a diminishment in another population cannot be ruled out. Thus, these data cannot absolutely rule out differentiation, proliferation, or survival effects on colony subsets. EGF maintains neurosphere cells with a predominantly primitive phenotype (nestin positive, lineage marker negative) and the continued presence of EGF appears to block the action of NTs on differentiation. Removal of EGF and the addition of NTs lead to lineage channeling toward neural and glial lineages without an effect on cell proliferation. These data suggest a model of sequential growth factor action on neural progenitors with EGF acting as a proliferation and survival factor and NTs inducing differentiation while maintaining the neurosphere colonies' proliferation over time. 


\section{Clinical Significance and Future Directions}

Understanding the physiological function of APP would allow us to gain insight into the molecular mechanisms behind the pathogenesis of AD. Such information would facilitate the development of novel therapeutic and even prophylactic strategies for the treatment of AD. Various studies have demonstrated a new role for APP in mediating the neurogenesis of progenitor cells within the hippocampus and SVZ of the adult brain. This has implications in the use of autologous stem cell replacement therapies in the repair of the adult $\mathrm{CNS}$ in $\mathrm{AD}$ patients in the near future. Current $\mathrm{AD}$ therapy serves only to reduce the degree of impairment and improve the quality of lives of patients. But the disease cannot be prevented or cured $[13,14,124$, 125]. The demonstration of active adult neurogenesis has since opened possibilities of repairing the mature CNS after degenerative neurological diseases like AD. Ongoing research promises a bright future for the clinical application of NSC strategies in neuro-replacement therapy for $\mathrm{AD}$ patients, and may potentially reverse the progression of the disease. Embryonic neural precursor cells provide an ideal alternative for transplantation in neurodegenerative diseases such as $\mathrm{AD}$, as they can be expanded in culture, thus avoiding many of the practical obstacles that limit the application of transplanting primary neurons. It has already been shown that human NSCs transplanted into aged rat brains can differentiate into neural cells and significantly improve the cognitive functions of animals, further pointing to NSCs as a promising candidate for neuroreplacement therapies $[100,103,104]$.

\section{Conclusion}

$\mathrm{AD}$ is a neurodegenerative disorder that currently affects nearly $2 \%$ of the population in industrialized countries. The risk of $\mathrm{AD}$ increases dramatically in individuals beyond the age of 70 and it is predicted that its incidence will increase threefold within the next 50 years. Brain regions involved in learning and memory processes, including the temporal and frontal lobes (the entorhinal cortex, hippocampus, basal forebrain and amygdala), are reduced in size in $\mathrm{AD}$ patients as a result of the degeneration of synapses and death of neurons. NSCs, with the capacity to self-renew and to produce the major cell types of the brain, exist in the developing and adult CNS. Their exact function and distribution is currently being assessed, but they represent an interesting cell population which may be used to study factors important for the differentiation of neurons, astrocytes and oligodendrocytes. There have been reports recently of the effects of NSC transplantation that attempt to obtain functional recovery from CNS damage and recent evidence suggests that NSCs may be a suitable source for the treatment of neurological diseases such as AD or Parkinson's disease. With an eye towards the development of NSCs replacement therapies, it is important to investigate the migration profile of NT-differentiated neurons and monitor the success of subsequent integrations into existing neuronal circuitries. The present review aims at gaining more insight into the functional role of the NTs on neurogenesis. Data indicate that NGF in particular may play a pivotal role in $\mathrm{AD}$ and the control of NSCs proliferation and differentiation. Loss of NGF functions may contribute to the progression of $\mathrm{AD}$ as impairment of neurogenesis is sufficient to deteriorate learning and memory. A promising approach for the treatment of $\mathrm{AD}$ is the application of NGF as a potential remedy. However, delivering NGF to the brain in an appropriate manner is still challenging because NGF does not cross the blood-brain barrier when applied peripherally. Even NGF causes intolerable side effects (including pain) if administered into the brain ventricular system. Recent experiments show that intranasal administration of NGF rescues recognition memory deficits in an anti-NGF transgenic mouse model which shows typical features of $\mathrm{AD}$ [49]. In addition, a brain site-specific gene delivery method provides sufficient quantities of NGF to support neuronal survival at restricted sites to avoid adverse side effects. A recent phase-I clinical trial of NGF gene therapy for $\mathrm{AD}$ already provides promising data $[126,127]$. In conclusion, NGF has been implicated in several new functions in the CNS, but much work remains to be done to explore the specific cross-talk between the NGF and APP systems and their specific role in neurogenesis. Such knowledge may then open new avenues for the treatment of neurodegenerative diseases such as $\mathrm{AD}$. 


\section{References}

1 Ip NY: The neurotrophins and neuropoietic cytokines: two families of growth factors acting on neural and hematopoietic cells. Ann NY Acad Sci 1998;840:97-106.

-2 Dechant G, Neumann H: Neurotrophins. Adv Exp Med Biol 2002;513:303-334.

-3 Huang EJ, Reichardt LF: Neurotrophins: roles in neuronal development and function. Annu Rev Neurosci 2001;24:677-736.

$\checkmark 4$ Huang EJ, Reichardt LF: Trk receptors: roles in neuronal signal transduction. Annu Rev Biochem 2003;72:609-642.

$\checkmark 5$ Hock C, Heese K, Muller-Spahn F, Hulette C, Rosenberg C, Otten U: Decreased trkA neurotrophin receptor expression in the parietal cortex of patients with Alzheimer's disease. Neurosci Lett 1998;241:151-154.

$\checkmark 6$ Hock C, Heese K, Hulette C, Rosenberg C, Otten U: Region-specific neurotrophin imbalances in Alzheimer disease: decreased levels of brain-derived neurotrophic factor and increased levels of nerve growth factor in hippocampus and cortical areas. Arch Neurol 2000;57:846-851.

$\checkmark 7$ Hock CH, Heese K, Olivieri G, Hulette CH, Rosenberg C, Nitsch RM, Otten U: Alterations in neurotrophins and neurotrophin receptors in Alzheimer's disease. J Neural Transm Suppl 2000;59:171-174.

8 Barker PA: p75NTR is positively promiscuous: novel partners and new insights. Neuron 2004;42:529-533.

-9 Peng S, Wuu J, Mufson EJ, Fahnestock M: Increased proNGF levels in subjects with mild cognitive impairment and mild Alzheimer disease. J Neuropathol Exp Neurol 2004;63: 641-649.

10 Pedraza CE, Podlesniy P, Vidal N, Arevalo JC, Lee R, Hempstead B, Ferrer I, Iglesias M, Espinet $\mathrm{C}$ : Pro-NGF isolated from the human brain affected by Alzheimer's disease induces neuronal apoptosis mediated by p75NTR. Am J Pathol 2005;166:533-543.

-11 Bayer TA, Wirths O, Majtenyi K, Hartmann T, Multhaup G, Beyreuther K, Czech C: Key factors in Alzheimer's disease: beta-amyloid precursor protein processing, metabolism and intraneuronal transport. Brain Pathol 2001; $11: 1-11$.

12 Selkoe DJ, Schenk D: Alzheimer's disease: molecular understanding predicts amyloid-based therapeutics. Annu Rev Pharmacol Toxicol 2003;43:545-584.

13 Mott RT, Hulette CM: Neuropathology of Alzheimer's disease. Neuroimaging Clin N Am 2005; 15:755-765.

14 Heese K, Akatsu H: Alzheimer's disease - an interactive perspective. Curr Alzheimer Res 2006;3:109-121.

15 Shivers BD, Hilbich C, Multhaup G, Salbaum M, Beyreuther K, Seeburg PH: Alzheimer's disease amyloidogenic glycoprotein: expression pattern in rat brain suggests a role in cell contact. EMBO J 1989;7:1365-1370.
16 Rosen DR, Martin-Morris L, Luo LQ, White $\mathrm{K}$ : A Drosophila gene encoding a protein resembling the human beta-amyloid protein precursor. Proc Natl Acad Sci USA 1989;86: 2478-2482.

17 Daigle I, Li C: Apl-1, a Caenorhabditis elegans gene encoding a protein related to the human beta-amyloid protein precursor. Proc Natl Acad Sci USA 1993;90:12045-12049.

18 Milward EA, Papadopoulos R, Fuller SJ, Moir RD, Small D, Beyreuther K, Masters CL: The amyloid protein precursor of Alzheimer's disease is a mediator of the effects of nerve growth factor on neurite outgrowth. Neuron 1992;9: 129-137.

19 Dawson GR, Seabrook GR, Zheng H, Smith DW, Graham S, O’Dowd G, Bowery BJ, Boyce S, Trumbauer ME, Chen HY, Van der Ploeg LH, Sirinathsinghji DJ: Age-related cognitive deficits, impaired long-term potentiation and reduction in synaptic marker density in mice lacking the beta-amyloid precursor protein. Neuroscience 1999;90:1-13

-20 Seabrook GR, Smith D W, Bowery BJ, Easter A, Reynolds T, Fitzjohn SM, Morton RA, Zheng H, Dawson GR, Sirinathsinghji DJ, Davies $\mathrm{CH}$, Collingridge GL, Hill RG: Mechanisms contributing to the deficits in hippocampal synaptic plasticity in mice lacking amyloid precursor protein. Neuropharmacology 1999;38:349-359.

21 Mattson MP, Barger SW, Cheng B, Lieberburg I, Smith-Swintosky VL, Rydel RE: Beta-amyloid precursor protein metabolites and loss of neuronal $\mathrm{Ca}^{2+}$ homeostasis in Alzheimer's disease. Trends Neurosci 1993;16:409-414.

22 Nishimoto I, Okamoto T, Matsuura Y, Takahashi S, Okamoto T, Murayama Y, Ogata E: Alzheimer amyloid protein precursor complexes with brain GTP-binding protein $\mathrm{G}(\mathrm{o})$. Nature 1993;362:75-79.

23 Okamoto T, Takeda S, Murayama Y, Ogata E, Nishimoto I: Ligand-dependent G protein coupling function of amyloid transmembrane precursor. J Biol Chem 1995;270:4205-4208.

24 Kosik KS: Alzheimer's disease: a cell biological perspective. Science 1992;256:780-783.

25 Neve RL, Finch EA, Dawes LR: Expression of the Alzheimer amyloid precursor gene transcripts in the human brain. Neuron 1988;1: 669-677.

26 Pollwein P, Masters CL, Beyreuther K: The expression of the amyloid precursor protein (APP) is regulated by two GC-elements in the promoter. Nucleic Acids Res 1992;20:63-68.

-27 Ohta M, Kitamoto T, Iwaki T, Ohgami T, Fukui M, Tateishi J: Immunohistochemical distribution of amyloid precursor protein during normal rat development. Brain Res Dev Brain Res 1993;75:151-161.

28 Sisodia SS, Koo EH, Beyreuther K, Unterbeck A, Price D: Evidence that $\beta$-amyloid protein in Alzheimer's disease is not derived by normal processing. Science 1990;248:492-495.
29 Vassar R, Citron M: Abeta-generating enzymes: recent advances in beta- and gammasecretase research. Neuron 2000;27:419-422.

30 Cao X, Sudhof TC: A transcriptionally [correction of transcriptively] active complex of APP with Fe65 and histone acetyltransferase Tip60. Science 2001;293:115-120.

-31 Cupers P, Bentahir M, Craessaerts K, Orlans I, Vanderstichele H, Saftig P, De Strooper B, Annaert W: The discrepancy between presenilin subcellular localization and gamma-secretase processing of amyloid precursor protein. J Cell Biol 2001;154:731-740.

-32 Cupers P, Orlans I, Craessaerts K, Annaert W, De Strooper B: The amyloid precursor protein (APP)-cytoplasmic fragment generated by gamma-secretase is rapidly degraded but distributes partially in a nuclear fraction of neurones in culture. J Neurochem 2001;78:11681178.

33 Zhao G, Mao G, Tan J, Dong Y, Cui MZ, Kim $\mathrm{SH}, \mathrm{Xu} \mathrm{X}$ : Identification of a new presenilindependent zeta-cleavage site within the transmembrane domain of amyloid precursor protein. J Biol Chem 2004;279:50647-50650.

34 Haass C, Koo E H, Mellon A, Hung AY, Selkoe DJ: Targeting of cell-surface beta-amyloid precursor protein to lysosomes: alternative processing into amyloid-bearing fragments. Nature 1992;357:500-503.

35 Grimm MO, Grimm HS, Patzold AJ, Zinser EG, Halonen R, Duering M, Tschape JA, De Strooper B, Muller U, Shen J, Hartmann T: Regulation of cholesterol and sphingomyelin metabolism by amyloid-beta and presenilin. Nat Cell Biol 2005;7:1118-1123.

36 Selkoe DJ: Normal and abnormal biology of the beta-amyloid precursor protein. Annu Rev Neurosci 1994;17:489-517.

37 Selkoe DJ: Cell biology of protein misfolding: the examples of Alzheimer's and Parkinson's diseases. Nat Cell Biol 2004;6:1054-1061.

38 Sisodia SS, St George-Hyslop PH: gammaSecretase, Notch, Abeta and Alzheimer's disease: where do the presenilins fit in? Nat Rev Neurosci 2002;3:281-290.

-39 Burdick D, Soreghan B, Kwon M, Kosmoski J, Knauer M, Henschen A, Yates J, Cotman C, Glabe C: Assembly and aggregation properties of synthetic Alzheimer's A4/beta amyloid peptide analogs. J Biol Chem 1992;267:546554.

40 Turner PR, O'Connor K, Tate WP, Abraham WC: Roles of amyloid precursor protein and its fragments in regulating neural activity, plasticity and memory. Prog Neurobiol 2003; 70:1-32.

41 Kamenetz F, Tomita T, Hsieh H, Seabrook G, Borchelt D, Iwatsubo T, Sisodia S, Malinow R: APP processing and synaptic function. Neuron 2003;37:925-937.

42 Mufson EJ, Li JM, Sobreviela T, Kordower JH: Decreased trkA gene expression within basal forebrain neurons in Alzheimer's disease. Neuroreport 1996;8:25-29. 
43 Lad SP, Neet KE, Mufson EJ: Nerve growth factor: structure, function and therapeutic implications for Alzheimer's disease. Curr Drug Targets CNS Neurol Disord 2003;2:315334.

44 Counts SE, Nadeem M, Wuu J, Ginsberg SD, Saragovi HU, Mufson EJ: Reduction of cortical TrkA but not p75(NTR) protein in earlystage Alzheimer's disease. Ann Neurol 2004; 56:520-531.

45 Counts SE, Mufson EJ: The role of nerve growth factor receptors in cholinergic basal forebrain degeneration in prodromal Alzheimer disease. J Neuropathol Exp Neurol 2005;64:263-272.

-46 Capsoni S, Ugolini G, Comparini A, Ruberti F, Berardi N, Cattaneo A: Alzheimer-like neurodegeneration in aged antinerve growth factor transgenic mice. Proc Natl Acad Sci USA 2000;97:6826-6831.

47 Capsoni S, Giannotta S, and Cattaneo A: Betaamyloid plaques in a model for sporadic Alzheimer's disease based on transgenic antinerve growth factor antibodies. Mol Cell Neurosci 2002;21:15-28.

- 48 Capsoni S, Giannotta S, Cattaneo A: Nerve growth factor and galantamine ameliorate early signs of neurodegeneration in anti-nerve growth factor mice. Proc Natl Acad Sci USA 2002;99:12432-12437.

-49 De Rosa R, Garcia AA, Braschi C, Capsoni S, Maffei L, Berardi N, Cattaneo A: Intranasal administration of nerve growth factor (NGF) rescues recognition memory deficits in AD11 anti-NGF transgenic mice. Proc Natl Acad Sci USA 2005; 102:3811-3816.

-50 Kamal A, Stokin GB, Yang Z, Xia CH, Goldstein LS: Axonal transport of amyloid precursor protein is mediated by direct binding to the kinesin light chain subunit of kinesin-I. Neuron 2000;28:449-459.

- 51 Kamal A, Almenar-Queralt A, LeBlanc JF, Roberts EA, Goldstein LS: Kinesin-mediated axonal transport of a membrane compartment containing beta-secretase and presenilin-1 requires APP. Nature 2001;414:643-648.

52 Gunawardena S, Goldstein LS: Disruption of axonal transport and neuronal viability by amyloid precursor protein mutations in Drosophila. Neuron 2001;32:389-401.

53 Heese K, Yamada T, Nagai Y, Sawada T: New aspect about APP signaling. Brain Aging 2003;3:15-20.

54 Heese K, Inoue N, Nagai Y, Sawada T: APP, NGF \& the 'Sunday-driver' in a trolley on the road. Restor Neurol Neurosci 2004;22:131136.

55 Muller U, Kins S: APP on the move. Trends Mol Med 2002;8:152-155.

-56 Kimberly WT, Zheng JB, Guenette SY, Selkoe DJ: The intracellular domain of the beta-amyloid precursor protein is stabilized by Fe65 and translocates to the nucleus in a notch-like manner. J Biol Chem 2001;276:40288-40292.
57 Kinoshita A, Whelan CM, Berezovska O, Hyman BT: The gamma secretase-generated carboxyl-terminal domain of the amyloid precursor protein induces apoptosis via Tip60 in $\mathrm{H} 4$ cells. J Biol Chem 2002;277:28530-28536.

58 Kinoshita A, Whelan CM, Smith CJ, Berezovska O, Hyman BT: Direct visualization of the gamma secretase-generated carboxyl-terminal domain of the amyloid precursor protein: association with Fe65 and translocation to the nucleus. J Neurochem 2002;82:839-847.

59 Sumioka A, Nagaishi S, Yoshida T, Lin A, Miura M, Suzuki T: Role of 14-3-3gamma in FE65-dependent gene transactivation mediated by the APP cytoplasmic fragment. J Biol Chem 2005;280:42364-42374.

60 Bowman AB, Kamal A, Ritchings BW, Philp AV, McGrail M, Gindhart JG, Goldstein LS: Kinesin-dependent axonal transport is mediated by the Sunday driver (SYD) protein. Cell 2000;103:583-594.

61 Klopfenstein DR, Vale RD, Rogers SL: Motor protein receptors: moonlighting on other jobs. Cell 2000;103:537-540.

62 Taru H, Iijima K, Hase M, Kirino Y, Yagi Y, Suzuki T: Interaction of Alzheimer's beta-amyloid precursor family proteins with scaffold proteins of the JNK signaling cascade. J Biol Chem 2002;277:20070-20078.

63 Ito M, Yoshioka K, Akechi M, Yamashita S, Takamatsu N, Sugiyama K, Hibi M, Nakabeppu Y, Shiba T, Yamamoto KI: JSAP1, a novel jun $\mathrm{N}$-terminal protein kinase (JNK)-binding protein that functions as a Scaffold factor in the JNK signaling pathway. Mol Cell Biol 1999;19:7539-7548.

64 Kelkar N, Gupta S, Dickens M, Davis RJ: Interaction of a mitogen-activated protein kinase signaling module with the neuronal protein JIP3. Mol Cell Biol 2000;20:1030-1043.

65 Verhey KJ, Meyer D, Deehan R, Blenis J, Schnapp BJ, Rapoport TA, Margolis B: Cargo of kinesin identified as JIP scaffolding proteins and associated signaling molecules. J Cell Biol 2001;152:959-970.

66 Yang DD, Kuan CY, Whitmarsh AJ, Rincon M, Zheng TS, Davis RJ, Rakic P, Flavell RA: Absence of excitotoxicity-induced apoptosis in the hippocampus of mice lacking the Jnk3 gene. Nature 1997;389:865-870.

67 Davis RJ: Signal transduction by the JNK group of MAP kinases. Cell 2000;103:239252.

68 Matsuura H, Nishitoh H, Takeda K, Matsuzawa A, Amagasa T, Ito M, Yoshioka K, Ichijo $\mathrm{H}$ : Phosphorylation-dependent scaffolding role of JSAP1/JIP3 in the ASK1-JNK signaling pathway. A new mode of regulation of the MAP kinase cascade. J Biol Chem 2002;277: 40703-40709.

69 Hashimoto Y, Tsuji O, Niikura T, Yamagishi Y, Ishizaka M, Kawasumi M, Chiba T, Kanekura K, Yamada M, Tsukamoto E, Kouyama K, Terashita K, Aiso S, Lin A, Nishimoto I: Involvement of c-Jun $\mathrm{N}$-terminal kinase in amyloid precursor protein-mediated neuronal cell death. J Neurochem 2003;84:864-877.
70 Cavalli V, Kujala P, Klumperman J, Goldstein LS: Sunday driver links axonal transport to damage signaling. J Cell Biol 2005;168:775787.

71 Marques CA, Keil U, Bonert A, Steiner B, Haass C, Muller WE, Eckert A: Neurotoxic mechanisms caused by the Alzheimer's disease-linked Swedish amyloid precursor protein mutation: oxidative stress, caspases, and the JNK pathway. J Biol Chem 2003;278: 28294-28302.

72 Liu HY, Meakin SO: ShcB and ShcC activation by the Trk family of receptor tyrosine kinases. J Biol Chem 2002;277:26046-26056.

73 Russo C, Dolcini V, Salis S, Venezia V, Zambrano N, Russo T, Schettini G: Signal transduction through tyrosine-phosphorylated Cterminal fragments of amyloid precursor protein via an enhanced interaction with Shc/ Grb2 adaptor proteins in reactive astrocytes of Alzheimer's disease brain. J Biol Chem 2002; 277:35282-35288.

74 Tarr PE, Contursi C, Roncarati R, Noviello C, Ghersi E, Scheinfeld MH, Zambrano N, Russo T, D’Adamio L: Evidence for a role of the nerve growth factor receptor TrkA in tyrosine phosphorylation and processing of beta-APP. Biochem Biophys Res Commun 2002;295:324329.

75 Tarr PE, Roncarati R, Pelicci G, Pelicci PG, D'Adamio L: Tyrosine phosphorylation of the beta-amyloid precursor protein cytoplasmic tail promotes interaction with Shc. J Biol Chem 2002;277:16798-16804.

76 von Bartheld CS, Wang X, Butowt R: Anterograde axonal transport, transcytosis, and recycling of neurotrophic factors: the concept of trophic currencies in neural networks. Mol Neurobiol 2001;24:1-28.

77 Campenot RB, MacInnis BL: Retrograde transport of neurotrophins: fact and function. J Neurobiol 2004;58:217-229.

78 Yano H, Chao MV: Mechanisms of neurotrophin receptor vesicular transport. J Neurobiol 2004;58:244-257.

79 Perini G, Della-Bianca V, Politi V, Della Valle G, Dal-Pra I, Rossi F, Armato U: Role of p75 neurotrophin receptor in the neurotoxicity by beta-amyloid peptides and synergistic effect of inflammatory cytokines. J Exp Med 2002; 195:907-918.

80 Yaar M, Zhai S, Fine RE, Eisenhauer PB, Arble BL, Stewart KB, Gilchrest BA: Amyloid beta binds trimers as well as monomers of the 75$\mathrm{kDa}$ neurotrophin receptor and activates receptor signaling. J Biol Chem 2002;277:77207725 .

81 Plant LD, Boyle JP, Smith IF, Peers C, Pearson HA: The production of amyloid beta peptide is a critical requirement for the viability of central neurons. J Neurosci 2003;23:5531-5535.

- 82 Tsukamoto E, Hashimoto Y, Kanekura K, Niikura T, Aiso S, Nishimoto I: Characterization of the toxic mechanism triggered by Alzheimer's amyloid-beta peptides via p75 neurotrophin receptor in neuronal hybrid cells. J Neurosci Res 2003;73:627-636. 
83 Zhang Y, Hong Y, Bounhar Y, Blacker M, Roucou X, Tounekti O, Vereker E, Bowers WJ, Federoff HJ, Goodyer CG, LeBlanc A: p75 neurotrophin receptor protects primary cultures of human neurons against extracellular amyloid beta peptide cytotoxicity. J Neurosci 2003;23:7385-7394.

84 Ceni C, Barker PA: Getting RIP'd stunts your growth. Neuron 2005;46:839-840.

85 Susen K, Blochl A: Low concentrations of aggregated beta-amyloid induce neurite formation via the neurotrophin receptor $\mathrm{p} 75$. J Mol Med 2005;83:720-735.

86 Okamoto T, Takeda S, Giambarella U, Murayama Y, Matsui T, Katada T, Matsuura Y, Nishimoto I: Intrinsic signaling function of APP as a novel target of three V642 mutations linked to familial Alzheimer's disease. EMBO J 1996;15:3769-3777.

-87 Kempermann G, Gage FH: New nerve cells for the adult brain. Sci Am 1999;280:48-53.

88 Gage FH: Mammalian neural stem cells. Science 2000;287:1433-1438.

-89 Lie DC, Dziewczapolski G, Willhoite AR, Kaspar BK, Shults CW, Gage FH: The adult substantia nigra contains progenitor cells with neurogenic potential. J Neurosci 2002;22: 6639-6649.

90 Okano H: Stem cell biology of the central nervous system. J Neurosci Res 2002;69:698-707.

-91 Brazel CY, Rao MS: Aging and neuronal replacement. Ageing Res Rev 2004;3:465-483.

92 Campos LS: Neurospheres: insights into neural stem cell biology. J Neurosci Res 2004;78: 761-769.

-93 Reynolds BA, Rietze RL: Neural stem cells and neurospheres - re-evaluating the relationship. Nat Methods 2005;2:333-336.

94 Ming GL, Song H: Adult neurogenesis in the mammalian central nervous system. Annu Rev Neurosci 2005;28:223-250.

-95 Shors TJ, Miesegaes G, Beylin A, Zhao M, Rydel T, Gould E: Neurogenesis in the adult is involved in the formation of trace memories. Nature 2001;410:372-376.

-96 Shors TJ: Memory traces of trace memories: neurogenesis, synaptogenesis and awareness. Trends Neurosci 2004;27:250-256.

97 Haughey NJ, Liu D, Nath A, Borchard AC, Mattson MP: Disruption of neurogenesis in the subventricular zone of adult mice, and in human cortical neuronal precursor cells in culture, by amyloid beta-peptide: implications for the pathogenesis of Alzheimer's disease. Neuromolecular Med 2002;1:125-135.

98 Haughey NJ, Nath A, Chan SL, Borchard AC, Rao MS, Mattson MP: Disruption of neurogenesis by amyloid beta-peptide, and perturbed neural progenitor cell homeostasis, in models of Alzheimer's disease. J Neurochem 2002;83:1509-1524.

-99 Calza L, Giuliani A, Fernandez M, Pirondi S, D'Intino G, Aloe L, Giardino L: Neural stem cells and cholinergic neurons: regulation by immunolesion and treatment with mitogens, retinoic acid, and nerve growth factor. Proc Natl Acad Sci USA 2003;100:7325-7330.
100 Oliveira AA Jr, Hodges HM: Alzheimer’s disease and neural transplantation as prospective cell therapy. Curr Alzheimer Res 2005;2: 79-95.

101 Lopez-Toledano MA, Shelanski ML: Neurogenic effect of beta-amyloid peptide in the development of neural stem cells. J Neurosci 2004;24:5439-5444.

102 Calafiore M, Battaglia G, Zappala A, Trovato-Salinaro E, Caraci F, Caruso M, Vancheri C, Sortino MA, Nicoletti F, Copani A: Progenitor cells from the adult mouse brain acquire a neuronal phenotype in response to beta-amyloid. Neurobiol Aging 2006;27: 606-613.

103 Sugaya K: Possible use of autologous stem cell therapies for Alzheimer's disease. Curr Alzheimer Res 2005;2:367-376.

104 Tanne JH: Activating stem cells may treat Alzheimer's. BMJ 2005;330:622.

105 Caille I, Allinquant B, Dupont E, Bouillot C, Langer A, Muller U, Prochiantz A: Soluble form of amyloid precursor protein regulates proliferation of progenitors in the adult subventricular zone. Development 2004;131: 2173-2181.

106 Conti L, Cattaneo E: Controlling neural stem cell division within the adult subventricular zone: An APPealing job. Trends Neurosci 2005;28:57-59.

107 Niles LP, Armstrong KJ, Rincon Castro LM, Dao CV, Sharma R, McMillan CR, Doering LC, Kirkham DL: Neural stem cells express melatonin receptors and neurotrophic factors: colocalization of the MT1 receptor with neuronal and glial markers. BMC Neurosci 2004;5:41.

108 Crigler L, Robey RC, Asawachaicharn A, Gaupp D, Phinney DG: Human mesenchymal stem cell subpopulations express a variety of neuro-regulatory molecules and promote neuronal cell survival and neuritogenesis. Exp Neurol 2006;198:54-64.

109 Gascon E, Vutskits L, Zhang H, Barral-Moran MJ, Kiss PJ, Mas C, Kiss JZ: Sequential activation of p75 and TrkB is involved in dendritic development of subventricular zone-derived neuronal progenitors in vitro. Eur J Neurosci 2005;21:69-80.

110 Arvidsson A, Collin T, Kirik D, Kokaia Z, Lindvall O: Neuronal replacement from endogenous precursors in the adult brain after stroke. Nat Med 2002;8:963-970.

111 Kirschenbaum B, Goldman SA: Brain-derived neurotrophic factor promotes the survival of neurons arising from the adult rat forebrain subependymal zone. Proc Natl Acad Sci USA 1995;92:210-214.

112 Shetty AK, Turner DA: In vitro survival and differentiation of neurons derived from epidermal growth factor-responsive postnatal hippocampal stem cells inducing effects of brain-derived neurotrophic factor. J Neurobiol 1998;35:395-425.
113 Cattaneo E, McKay R: Proliferation and differentiation of neuronal stem cells regulated by nerve growth factor. Nature 1990;347: 762-765.

114 Hosomi S, Yamashita T, Aoki M, Tohyama $\mathrm{M}$ : The p75 receptor is required for BDNFinduced differentiation of neural precursor cells. Biochem Biophys Res Commun 2003; 301:1011-1015.

115 Lachyankar MB, Condon PJ, Quesenberry PJ, Litofsky NS, Recht LD, Ross AH: Embryonic precursor cells that express Trk receptors: Induction of different cell fates by NGF, BDNF, NT-3, and CNTF. Exp Neurol 1997; 144:350-360.

116 Benoit BO, Savarese T, Joly M, Engstrom CM, Pang L, Reilly J, Recht LD, Ross AH, Quesenberry PJ: Neurotrophin channeling of neural progenitor cell differentiation. J Neurobiol 2001;46:265-280.

117 Althaus HH: Remyelination in multiple sclerosis: a new role for neurotrophins? Prog Brain Res 2004;146:415-432.

118 Du Y, Fischer TZ, Lee LN, Lercher LD, Dreyfus CF: Regionally specific effects of BDNF on oligodendrocytes. Dev Neurosci 2003;25: 116-126.

119 Kumar S, Kahn MA, Dinh L, de Vellis J: NT3-mediated TrkC receptor activation promotes proliferation and cell survival of rodent progenitor oligodendrocyte cells in vitro and in vivo. J Neurosci Res 1998;54: 754-765.

120 Wang Y, Hagel C, Hamel W, Muller S, Kluwe L, Westphal M: Trk A, B, and C are commonly expressed in human astrocytes and astrocytic gliomas but not by human oligodendrocytes and oligodendroglioma. Acta Neuropathol (Berl) 1998;96:357-364.

121 Jin L, Hu X, Feng L: NT3 inhibits FGF2-induced neural progenitor cell proliferation via the PI3K/GSK3 pathway. J Neurochem 2005; 93:1251-1261.

122 Ahmed S, Reynolds BA, Weiss S: BDNF enhances the differentiation but not the survival of CNS stem cell-derived neuronal precursors. J Neurosci 1995; 15:5765-5778.

123 Reynolds BA, Weiss S: Clonal and population analyses demonstrate that an EGF-responsive mammalian embryonic CNS precursor is a stem cell. Dev Biol 1996;175: $1-13$.

124 Helmuth L: New therapies. New Alzheimer's treatments that may ease the mind. Science 2002;297:1260-1262.

125 Rosenberg RN: Immunotherapy for Alzheimer disease: the promise and the problem. Arch Neurol 2005;62:1506-1507.

126 Tuszynski MH, Thal L, Pay M, Salmon DP, U HS, Bakay R, Patel P, Blesch A, Vahlsing HL, Ho G, Tong G, Potkin SG, Fallon J, Hansen L, Mufson EJ, Kordower JH, Gall C, Conner $\mathrm{J}$ : A phase 1 clinical trial of nerve growth factor gene therapy for Alzheimer disease. Nat Med 2005;11:551-555.

$>127$ Bradbury J: Hope for AD with NGF genetherapy trial. Lancet Neurol 2005;4:335. 